\title{
Author Correction: Uplift of the central transantarctic mountains
}

\author{
Phil Wannamaker (10 1, Graham Hill 2,3,4, John Stodt ${ }^{5}$, Virginie Maris ${ }^{1}$, Yasuo Ogawa (D) ${ }^{6}$, Kate Selway ${ }^{7}$, \\ Goran Boren $^{8}$, Edward Bertrand ${ }^{9}$, Daniel Uhlmann ${ }^{10}$, Bridget Ayling ${ }^{11}$, A. Marie Green ${ }^{12}$ \& Daniel Feucht ${ }^{13}$
}

Correction to: Nature Communications https://doi.org/10.1038/s41467-017-01577-2, published online 17 November 2017

The original version of this Article incorrectly referenced the Figures in the Supplementary Information. References in the main Article to Supplementary Figure 7 through to Supplementary Figure 20 were previously incorrectly cited as Supplementary Figure 5 through to Supplementary Figure 18, respectively. This has now been corrected in both the PDF and HTML versions of the Article.

Published online: 16 February 2018 \begin{abstract}
reproduction in any medium or format, as long as you give appropriate credit to the original author(s) and the source, provide a link to the Creative Commons license, and indicate if changes were made. The images or other third party material in this article are included in the article's Creative Commons license, unless indicated otherwise in a credit line to the material. If material is not included in the article's Creative Commons license and your intended use is not permitted by statutory regulation or exceeds the permitted use,
\end{abstract} you will need to obtain permission directly from the copyright holder. To view a copy of this license, visit http://creativecommons.org/licenses/by/4.0/.

(C) The Author(s) 2018

\footnotetext{
${ }^{1}$ University of Utah/Energy \& Geoscience Institute, Salt Lake City, UT 84108, USA. ${ }^{2}$ University of Canterbury, Gateway Antarctica, 8041 Christchurch, New Zealand. ${ }^{3}$ Antarctica Scientific Ltd, 6011 Wellington, New Zealand. ${ }^{4}$ Formerly at GNS Science, Natural Hazards Division, 5011 Lower Hutt, New Zealand. ${ }^{5}$ Numeric Resources LLC, Salt Lake City, UT 84108, USA. ${ }^{6}$ Tokyo Institute of Technology, Volcanic Fluid Research Center, 152-8550 Tokyo, Japan.

7 Department of Earth and Planetary Sciences, Macquarie University, Sydney, NSW 2109, Australia. ${ }^{8}$ Department of Geology \& Geophysics, University of Adelaide, Adelaide, SA 5005, Australia. ${ }^{9}$ GNS Science, Natural Hazards Division, 5011 Lower Hutt, New Zealand. ${ }^{10}$ First Light Mountain Guides, 74400 Chamonix, France. ${ }^{11}$ Great Basin Center for Geothermal Energy, University of Nevada, Reno, NV 89557, USA. ${ }^{12}$ Department of Geology \& Geophysics, University of Utah, Salt Lake City, UT 84112, USA. ${ }^{13}$ Department of Geological Sciences, University of Colorado, Boulder, CO 80309, USA. Correspondence and requests for materials should be addressed to P.W. (email: pewanna@egi.utah.edu)
} 